\title{
Immediate flow reserve of $Y$ thoracic artery grafts: An intraoperative flowmetric study
}

\author{
Mario Gaudino, MD* \\ Michele Di Mauro, MD \\ Angela Lorena lacò, MD \\ Carlo Canosa, MD \\ Giuseppe Vitolla, MD \\ Antonio Maria Calafiore, MD
}

\footnotetext{
From the Department of Cardiology and Cardiac Surgery, "G. D’Annunzio" University, Chieti, Italy.

Received for publication July 18, 2002; revisions requested Sept 3, 2002; revisions received Dec 2, 2002; accepted for publication Dec 19, 2002.

Address for reprints: Antonio Maria Calafiore, MD, "G. D'Annunzio" University, Division of Cardiac Surgery, c/o S. Camillo de' Lellis Hospital, via C. Forlanini, 50, 66100, Chieti, Italy (E-mail: calafiore@ unich.it).

*Current address: Division of Cardiac Surgery, Catholic University, Rome, Italy.

J Thorac Cardiovasc Surg 2003;126:1076-9

Copyright (C) 2003 by The American Association for Thoracic Surgery

$0022-5223 / 2003 \$ 30.00+0$

doi:10.1016/S0022-5223(03)00122-3
}

Objectives: Use of both internal thoracic arteries in a $\mathrm{Y}$ graft configuration can raise concerns about the possibility of the single left internal thoracic artery being able to meet the flow requirements of two or three distal territories. We evaluated intraoperatively the flow reserve of a Y thoracic artery graft distally anastomosed to the anterior and lateral territories.

Methods: In 21 patients who had Y thoracic artery grafts, the flow was measured in the main stem of the left internal thoracic artery, in the left internal thoracic artery branch, and in the right internal thoracic artery. A transit time Doppler flowmeter was used. Measurements were repeated after the injection of a bolus of $20 \mu \mathrm{g} / \mathrm{kg}$ dobutamine.

Results: At baseline condition, the mean blood flow was $44.8 \pm 24.2,23.4 \pm 11.5$, and $21.4 \pm 15.3 \mathrm{~mL} / \mathrm{min}$ in the main stem of the left internal thoracic artery, in the left internal thoracic artery branch, and in the right internal thoracic artery, respectively. After dobutamine injection, these values increased to $93.2 \pm 49.8,46.1 \pm$ 22.6 , and $42.5 \pm 31.2 \mathrm{~mL} / \mathrm{min}$, respectively. Flow reserve was $2.1 \pm 0.6,2.2 \pm 0.9$, and $2.1 \pm 0.9 \mathrm{~mL} / \mathrm{min}$, respectively.

Conclusions: Intraoperative injection of dobutamine increases the flow in the $\mathrm{Y}$ thoracic graft by more than two times, not only in the main stem but also in each branch. This finding attests to the safety of $\mathrm{Y}$ thoracic conduits in terms of hemodynamic potential.

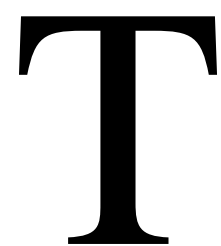

he adoption of composite thoracic artery conduits (either a $\mathrm{Y}$ or $\mathrm{T}$ configuration) has been advocated by several authors to maximize the benefits of thoracic artery revascularization. ${ }^{1-4}$

However, this technical solution implies that all coronary bypass flow is furnished by a single source, rendering several (if not all) myocardial territories dependent on the proximal part of the left thoracic artery. To date, limited information on the $\mathrm{Y}$ graft's flow reserve is available; concerns have been raised regarding the possibility of a hypoperfusion syndrome (at least in stress conditions) when these composite conduits are adopted.

The present study was conceived to determine the immediate flow reserve of $Y$ thoracic artery conduits by means of intraoperative flow measurement at rest and in stress conditions.

\section{Patients and Methods}

Patient Population

This report is based on data derived from 21 elective patients, with isolated double or triple vessel disease, who were referred for surgical myocardial revascularization at our institution 
between January 7 and August 28, 2000. Selection for the present investigation was based on the willingness of the patient to participate and on the technical possibility of using a Y thoracic artery graft for the coronary bypass procedure.

\section{Surgical Technique}

The surgical technique used has been described elsewhere. ${ }^{5}$ The majority of the operations $(11 / 21)$ were performed with normothermic cardiopulmonary bypass; for the others, our previously described no-pump method was used. ${ }^{6}$

\section{Intraoperative Measurements}

After completion of the last anastomosis, patients were weaned from extracorporeal circulation (for those cases in which the heart-lung machine was used). Hemodynamic stabilization blood flow was measured in the main stem of the left thoracic artery (LMS) as well as in the two branches of the Y graft (left internal thoracic artery [LITA] and right internal thoracic artery [RITA], respectively) using a dedicated flowmeter (Cardiomed, Medi-Stim, Oslo, Norway). After careful evaluation of the morphologic appearance of the flowmetric curve and of the flow value, only cases in which there was a wide diastolic waveform and a mean blood flow of $10 \mathrm{~mL} / \mathrm{min}$ or more were considered acceptable. All the cases in the present study fulfilled these criteria.

Mean blood flow in the LMS, LITA, and RITA was then recorded, taking care to maintain a mean arterial pressure of almost $70 \mathrm{~mm} \mathrm{Hg}$.

A $20 \mu \mathrm{g} / \mathrm{kg}$ dobutamine bolus (Dobutrex, Eli Lilly Italia, Sesto Fiorentino, Italy) was then injected into the patients and all the measurements were repeated when the double product (heart rate $\times$ systolic blood pressure) was greater than 10,000 .

Coronary flow reserve (CRF) was obtained from the ratio of the maximum to the baseline flow in each segment where the flow was recorded.

\section{Statistical Analysis}

Results are expressed as mean value \pm SD unless otherwise indicated. Statistical analysis comparing two groups was performed with paired 2-tailed $t$ testing for the mean. (SPSS software, SPSS, Inc, Chicago, Ill).

\section{Results}

In all our patients, the double product reached over 10,000. The mean preoperative characteristics of the 21 patients selected for our study are summarized in Table 1; the main intraoperative data are shown in Table 2.

No patient had major perioperative complications, and the mean postoperative peak creatine kinase $\mathrm{MB}$ value was $25.3 \pm 16.8 \mathrm{IU} / \mathrm{L}$.

The LITA branch of the Y thoracic grafts was used to revascularize the left anterior descending artery, whereas the RITA was anastomosed to the obtuse marginal branch in all cases. In no case was the RITA used to graft the distal branches of the right coronary artery.

Hemodynamic and flow measurement values at baseline and after dobutamine administration are summarized in
TABLE 1. Preoperative characteristics of the patients

\begin{tabular}{lc}
\hline Characteristic & Patient(s) \\
\hline Mean age (y) & $61.7 \pm 10.5$ \\
Age $\geq 75 \mathrm{y}$ & 2 \\
Female & 1 \\
Hypertension & 8 \\
Diabetes & 4 \\
Dyslipemia & 7 \\
Smoking history & 8 \\
Previous AMI & 13 \\
Cerebrovascular disease & 1 \\
Left main disease & 2 \\
Two vessel disease & 6 \\
Three vessel disease & 15 \\
Mean EF & $0.58 \pm 0.18$ \\
EF $\leq 0.35$ & 2 \\
\hline
\end{tabular}

$A M I$, Acute myocardial infarction; $E F$, ejection fraction.

\section{TABLE 2. Operative data}

\begin{tabular}{lc}
\hline Characteristic & Data \\
\hline CPB use & 11 \\
Mean CPB time (min)* & $68.1 \pm 20.9$ \\
Mean crossclamp time (min)* & $61.1 \pm 20.8$ \\
Anastomoses (per patient) & $3.2 \pm 0.8$ \\
BITA anastomoses (per patient) & $2.3 \pm 0.6$ \\
ITA sequential grafts & 7 \\
RA & 5 \\
SVG & 12 \\
\hline
\end{tabular}

$B I T A$, Bilateral internal thoracic artery; $C P B$, cardiopulmonary bypass; ITA, internal thoracic artery; $R A$, radial artery; $S V G$, saphenous vein graft.

${ }^{*}$ Applicable to the 11 patients in whom cardiopulmonary bypass was used.

Table 3. At baseline condition, the mean blood flow in the LMS, the LITA, and the RITA was $44.8 \pm 24.2,23.4 \pm$ 11.5 , and $21.4 \pm 15.3 \mathrm{~mL} / \mathrm{min}$, respectively. After dobutamine injection, these values increased to $93.2 \pm 49.8,46.1$ \pm 22.6 , and $42.5 \pm 31.2 \mathrm{~mL} / \mathrm{min}$, respectively, showing a more than twofold increase in capacity of the $\mathrm{Y}$ conduits in response to the moderate increase in double product caused by the dobutamine injection. CRF was $2.1 \pm 0.6,2.2 \pm 0.9$, and $2.1 \pm 0.9 \mathrm{~mL} / \mathrm{min}$, respectively.

The flow increase in the LMS, the LITA, and the RITA reached, in all cases, $P<.001$.

All patients had a good postoperative recovery and were discharged from the hospital after a mean of $4.4 \pm 1.3$ days. After $23.3 \pm 5.9$ months from surgery, no case of clinical evidence of ischemia recurrence was reported. All the patients underwent myocardial scintigraphy that showed no ischemia in the territories grafted with both ITAs.

\section{Comment}

The use of composite ( $\mathrm{Y}$ or $\mathrm{T})$ thoracic grafts has been proposed by several groups to maximize the benefits of thoracic artery grafting and to widen the spectrum of cases 
TABLE 3. Hemodynamic and flowmetric measurements

\begin{tabular}{lccr}
\hline Measurement & Baseline & After dobutamine injection & $P$ value \\
\hline Heart rate (beats/min) & $77.2 \pm 10.6(58-90)$ & $94.4 \pm 12.4(75-120)$ & CRF \\
Systolic blood pressure (mm Hg) & $97.0 \pm 11.5(80-120)$ & $128.8 \pm 19.0(100-180)$ & $<.001$ \\
Diastolic blood pressure (mm Hg) & $61.0 \pm 12.0(50-78)$ & $78.0 \pm 11.0(66-95)$ & $<.001$ \\
Double product & $7464 \pm 1248($ range) & $12087 \pm 2395($ range $)$ & $<.001$ \\
LTA flow (ml/min) & $44.8 \pm 24.2(16.5-110)$ & $93.2 \pm 49.8(36.6-230)$ & $<.001$ \\
LITA flow (ml/min) & $23.4 \pm 11.5(5.1-48.5)$ & $46.1 \pm 22.6(15-115)$ & $<.001$ \\
RITA flow (ml/min) & $21.4 \pm 15.3(1.7-52)$ & $42.5 \pm 31.2(5.8-138)$ & $<.001$ \\
\end{tabular}

Data are expressed as mean, $S D$, and range. CRF, Coronary flow reserve; LITA, left internal thoracic artery; LMS, main stem of the left internal thoracic artery; RITA, right internal thoracic artery.

in which total arterial revascularization can be achieved by using only the gold standard coronary artery bypass conduit. ${ }^{1-4}$

Our group ${ }^{5}$ has shown that the adoption of $\mathrm{Y}$ grafts allows the performance of a greater number of anastomoses and a wider myocardial revascularization than does the use of both in situ thoracic arteries; furthermore, $\mathrm{Y}$ grafts do not carry any detrimental effect in terms of early clinical outcome and midterm angiographic patency.

To date, the thoracic artery is the only arterial conduit for which a solid demonstration of excellent long-term patency and clinical benefits is available (for all the others, such advantages are still only speculative). It can be hypothesized that the adoption of composite thoracic grafts can represent the optimal modality of surgical myocardial revascularization by allowing the performance of most (if not all) anastomoses using the ideal conduit.

However, the major concerns related to the widespread adoption of the composite thoracic grafts arise from the lack of substantial data on their flow capacity and the hypothesized possibility that such conduits can be unable to provide sufficient flow to two or three coronary territories, especially in the early postoperative period and in a condition of increased myocardial oxygen request. ${ }^{4}$

The present study was conceived to investigate the flow capacity of $Y$ thoracic grafts in the period immediately after their construction. This time frame was selected because, at that moment, the thoracic artery has not yet undergone the described progressive adaptation to the postoperative increase in flow demand, so that if the possibility of a Y graft insufficiency exists, this time period should be the one of highest risk.

Our data demonstrate how, in the immediate postconstruction period, the $\mathrm{Y}$ thoracic conduit has the potential to augment its flow more than 2-fold in response to the moderate increase in myocardial oxygen request elicited by dobutamine injection. This happens not only in the main LMS but also in both of its branches. Although without metabolic data the presence of a subclinical degree of myocardial ischemia cannot be definitely ruled out, this wide capacity of flow increase, combined with the absence of clinical and electrocardiographic evidence of ischemia in the operating room and in the early postoperative period and the low creatine kinase MB value in all study patients, strongly argues against any possible $\mathrm{Y}$ graft insufficiency.

These findings are in accord with those reported by Royse and colleagues ${ }^{7}$ (who described a 2.3-fold reserve of composite thoracic and radial artery grafts intraoperatively) and by Wendler and associates ${ }^{8}$ (who found in $\mathrm{T}$ thoracic grafts a flow capacity of $1.85 \pm 0.31 \mathrm{~mL} / \mathrm{min}$ at 1 week after surgery and $2.77 \pm 0.77 \mathrm{~mL} / \mathrm{min} 6$ months postoperatively). More recently, investigations performed 6 months after surgery confirmed the effectiveness of composite thoracic artery grafts after dobutamine stress echocardiography. ${ }^{9}$ Markwirth and colleagues ${ }^{10}$ found that, 6 months after surgery, flow reserve in the T thoracic graft was $2.79 \pm 0.92$ $\mathrm{mL} / \mathrm{min}$. It was similar to the flow reserve in the LITA radial artery $\mathrm{T}$ graft $(2.85 \pm 0.99 \mathrm{~mL} / \mathrm{min})$ and was not influenced by the presence of one or more occluded distal territories. The results of our study show that the flow reserve that can be detected in acute dobutamine stress test intraoperatively is similar to the flow reserve that can be found in the late follow-up.

From our data, it is impossible to establish whether the observed increase in thoracic artery flow is mainly a consequence of the greater myocardial oxygen demand or of the increased systolic blood pressure and cardiac output. However, as the two conditions usually coexist in clinical practice, this theoretical issue seems to have minor practical implications. Similarly, our observations do not allow us to predict the patterns of flow into the different coronary territories. However, this study was intended to evaluate the immediate flow reserve of $\mathrm{Y}$ thoracic artery grafts and their capacity for serving more than one coronary bed under stress condition in the immediate postoperative period and did not pretend to schematize a complex issue such as the flow dynamics of composite grafts. The relative flow distribution would be dependent on the sizes of the respective coronary beds, the sizes of the grafted vessels, and the degree of native coronary stenosis; it is likely to be different from patient to patient. The operating surgeon must carefully evaluate the anatomic and physiologic aspects of the 
single case to identify the eventual contraindications to $\mathrm{Y}$ graft adoption, independently from every theoretical attempt to schematize or predict flow dynamics.

Even though further investigations on this subject are mandatory before recommending the routine adoption of $\mathrm{Y}$ grafts, our observations attest to the safety of $\mathrm{Y}$ thoracic conduits, in terms of hemodynamic potential, and provide an objective demonstration of their flow capacity even in the immediate postoperative period.

At present, the $\mathrm{Y}$ thoracic graft technique should be regarded as safe and effective and probably always should be adopted in those patients who are most likely to benefit from complete thoracic artery revascularization. The Y graft is able to substantially increase its flow, not only in the LMS but also in both branches.

\section{References}

1. Weisnchelbaum E, Gabe E, Macchia A, Smimmo R, Suarez L. Total myocardial revascularization with arterial conduits: radial artery combined with internal thoracic arteries. J Thorac Cardiovasc Surg. 1997; 114:911-6.

2. Calafiore AM, Di Giammarco G, Luciani N, Maddestra N, Di Nardo
E, Angelini R. Composite arterial conduits for a wider arterial myocardial revascularization. Ann Thorac Surg. 1994;58:185-90.

3. Chocron S, Etievent JP, Schiele F, Clement F, Alwan K, Cordier A, et al. The Y graft: myocardial revascularization with both internal thoracic arteries: evaluation of eighty cases with coronary angiographic assessment. J Thorac Cardiovasc Surg. 1994;108:736-40.

4. Tector A, Amunden S, Schmahl T, Kress D, Peter M. Total revascularization with T grafts. Ann Thorac Surg. 1994;108:736-40.

5. Calafiore AM, Contini M, Vitolla G, Di Mauro M, Mazzei V, Teodori $\mathrm{G}$, et al. Bilateral internal thoracic artery grafting: long-term clinical and angiographic results of in situ versus Y grafts. $J$ Thorac Cardiovasc Surg. 2000;120:990-8.

6. Calafiore AM, Teodori G, Di Giammarco G, Vitolla G, Maddestra N, Paloscia L, et al. Multiple arterial conduits without cardiopulmonary bypass: early angiographic results. Ann Thorac Surg. 1999;67:450-6.

7. Royse AG, Royse CF, Groves KL, Bus B, Yu G. Blood flow in composite arterial grafts and effect of native coronary flow. Ann Thorac Surg. 1999;68:1619-22.

8. Wendler O, Hennen B, Markwirth T, Konig J, Tscholl D, Huang Q, et al. $\mathrm{T}$ grafts with the right internal thoracic artery to left internal thoracic artery versus the left internal thoracic artery and radial artery: flow dinamics in the internal thoracic artery main stem. $J$ Thorac Cardiovasc Surg. 1999;118:841-8.

9. Ochi M, Hatori N, Bessho R, Fujii M, Saji Y, Tanaka S, et al. Adequacy of flow capacity of bilateral internal thoracic artery $\mathrm{T}$ graft. Ann Thorac Surg. 2001;72:2008-12.

10. Markwirth T, Hennen B, Scheller B, Schäfers H-J, Wendler O. Flow wire measurement after complete arterial coronary revascularization with T-grafts. Ann Thorac Surg. 2001;71:788-93. 